\title{
Primary dystonia, DYT2 type
}

INSERM

\section{Source}

INSERM. (1999). Orphanet: an online rare disease and orphan drug data base. Primary dystonia, DYT 2 type. ORPHA:99657

Primary dystonia DYT 2 type is characterized by segmental dystonia that manifests with involuntary posturing affecting predominantly the feet. 